\author{
ANDRZEJ WRÓBEL \\ Cognitive Science \\ Institute of Philosophy \\ University of Warsaw \\ 3 Krakowskie Przedmiescie Str., 00-927 Warszawa \\ e-mail: andrzej.wrobel@uw.edu.pl
}

\title{
HOW DOES THE MIND EMERGE - FINDINGS FROM CONTEMPORARY BRAIN RESEARCH - INTRODUCTION
}

Neuroscience is currently the most dynamically expanding branch of science. In developed countries it is generously supported by state grants as a result of the rapidly mounting costs for neurological and psychiatric patient care. These costs result from increasing stress in everyday life as well as from aging of societies. Despite wide recognition more than two decades have passed since the last, special issue of KOSMOS which was entirely devoted to methods of brain research (To see the thought 46/3, 1997, edited by Andrzej Wróbel and Stefan Kasicki). This issue was, and still is, a great success and remains cited and read by students of neurobiological and cognitive studies. However, the techniques used by neuroscientists have rapidly developed and the scope of brain research has broadened since then.

The current issue introduces the reader to state-of-the-art techniques used in contemporary experimental and clinical neuroscience and explains some of the new, and emerging, topics investigated by researchers across the world. The topics covered include molecular, neuronal and network processing, cognitive search for mind, and neuroinformatic modelling, in health and disease. The articles have been written mainly by young researchers from leading laboratories in Poland, and Polish scientists working in internationally-recognized universities abroad. This issue is prefaced by a short biography of Prof. Jerzy Konorski, the founder of the modern Polish school of neuroscience, longterm Head of the Department of Neurophysiology, and Director of the Nencki Institute of Experimental Biology.

Each article contained in this issue of Kosmos has been written clearly enough, and in sufficient detail, for undergraduates and graduates of neurobiology/cognitive science, and also for general readers interested in the current issues face by the neuroscience community.

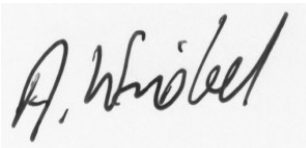

